\title{
3,5,4'-Tri-O-acetylresveratrol decreases seawater inhalation-induced acute lung injury by interfering with the NF-кB and i-NOS pathways
}

\author{
LIJIE MA $^{1 *}$, XIANGJUN CHEN $^{1 *}$, RUIXUAN WANG $^{1}$, HONGTAO DUAN $^{3}$, LIBIN WANG $^{4}$, \\ LI LIANG ${ }^{4}$, YANDONG NAN ${ }^{1}$, XUEYING LIU ${ }^{4}$, AO LIU ${ }^{2}$ and FAGUANG JIN ${ }^{1}$
}

\begin{abstract}
${ }^{1}$ Department of Respiration, Tangdu Hospital, The Fourth Military Medical University, Xi'an, Shaanxi 710038;
${ }^{2}$ Department of Respiration, Kunming General Hospital of Chengdu Military Command, Kunming, Yunnan 650032;

${ }^{3}$ Department of Thoracic Surgery, Tangdu Hospital, The Fourth Military Medical University, Xi'an, Shaanxi 710038;

${ }^{4}$ Department of Medicinal Chemistry, School of Pharmacy, The Fourth Military Medical University, Xi'an, Shaanxi 710032, P.R. China
\end{abstract}

Received April 9, 2015; Accepted October 27, 2015

DOI: 10.3892/ijmm.2015.2403

\begin{abstract}
Drowning is a cause of accidental mortality. However, survival may result in acute lung injury. The aim of the present study was to evaluate the effects of 3,5,4'-tri-O-acetylresveratrol (AC-Res) on acute lung injury (ALI) induced by seawater inhalation in rats. ALI models were established by the tracheal instillation of artificial seawater with or without $50 \mathrm{mg} / \mathrm{kg}$ AC-Res pretreatment for 7 days. Lung samples from different groups were harvested $4 \mathrm{~h}$ after the model was established. Histological changes, blood vessel permeability, inflammatory factor secretion and expression states of the nuclear factor- $\mathrm{\kappa B}$ (NF- $\kappa \mathrm{B})$ and inducible NOS (i-NOS) pathway were assessed to evaluate seawater-induced lung injury and the protective effects of acetylated resveratrol. The results showed that seawater inspiration led to physiological structure changes and an increased permeability of blood vessels. In addition, seawater stimulation enhanced the expression levels of nitric oxide (NO), tumor necrosis factor $\alpha$ (TNF- $\alpha$ ) and interleukin-1 $\beta$ (IL-1 $\beta$ ) secretion in vitro and in vivo. Notably, seawater inhalation increased NF- $\mathrm{KB}$ and $\mathrm{i}-\mathrm{NOS}$ expression in lungs and cells. On the other hand, pretreatment of AC-Res inhibited the abnormal expression of the NF- $\mathrm{kB}$ and i-NOS pathways, followed by decreased NO, TNF- $\alpha$ and IL- $1 \beta$ secretion, protein
\end{abstract}

Correspondence to: Professor Faguang Jin, Department of Respiration, Tangdu Hospital, The Fourth Military Medical University, No. 1 Xinsi Road, Xi'an, Shaanxi 710038, P.R. China

E-mail: jinfag@fmmu.edu.cn

Professor Ao Liu, Department of Respiration, Kunming General Hospital of Chengdu Military Command, 212 Daguan Road, Kunming, Yunnan 650032, P.R. China

E-mail: ynkm43@126.com

${ }^{*}$ Contributed equally

Key words: seawater, acute lung injury, nuclear factor- $\kappa \mathrm{B}$, inducible nitric oxide synthases, 3,5,4'-tri-O-acetylresveratrol and cell content in bronchoalveolar lavage fluid (BALF) and Evans blue, protein and cell infiltration from blood vessels into lung tissues. The results therefore suggest that AC-Res attenuated seawater inhalation induced-ALI by interfering with the NF- $\mathrm{kB}$ and i-NOS pathways.

\section{Introduction}

Drowning is a cause of accidental mortality. However, survival of the initial apnoea may result in acute lung injury (ALI) (1). The symptoms of near drowning depend on the composition (2) and quantity of water aspirated (3) and it is well known that ALI induced by seawater (SW-ALI) is more severe than that of fresh water. Additionally, SW-ALI is more complicated than ordinary ALI because hypertonic stimulation is unique for seawater-induced lung injury compared with other types of ALI (4). Seawater inspiration may result in direct and indirect disorders, such as histological changes, alveolar epithelial cell apoptosis and injuries associated with its physical properties $(5,6)$. Following direct injury, the infiltration of inflammatory cells may aggravate lung damage and the stimulated inflammatory cells release various molecules such as pro-inflammatory cytokines, reactive oxygen species and proteases, exacerbating the pulmonary inflammatory process (7). Therefore, it may be beneficial for SW-ALI to inhibit inflammation following seawater inspiration.

Mounting evidence shown that nuclear factor- $\mathrm{\kappa B}(\mathrm{NF}-\mathrm{\kappa B})$ is a crucial transcriptional factor in regulating inflammatory factors and plays a key role in the initiation and amplification of immune and inflammatory responses (8). In most cells, the primary form of NF- $\kappa \mathrm{B}$, consisting of a heterodimer of p50 and $\mathrm{p} 65$, localizes in the cytoplasm and binds to inhibitory proteins known as IкB families. Once stimulated by activators, such as LPS, tumor necrosis factor $\alpha$ (TNF- $\alpha$ ), IL-1 and

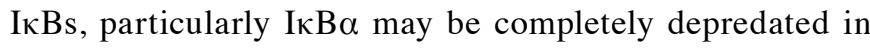
minutes (9). Released NF- $\kappa B$ translocates into the nucleus and binds to a variety of associated target DNA sequences known as $\kappa \mathrm{B}$ sites to modulate the associated gene expression. 


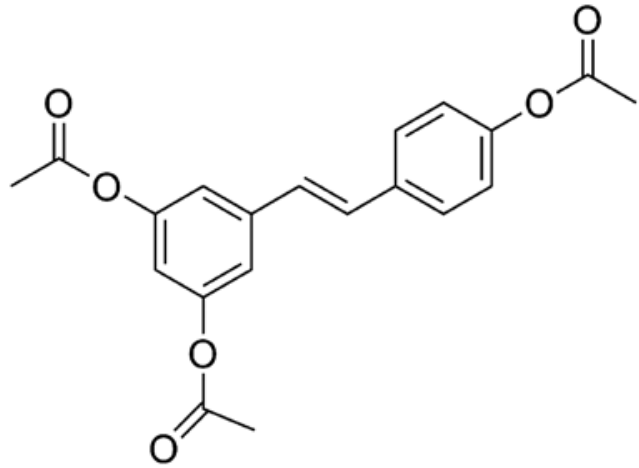

Figure 1. The structure of 3,5,4'-tri-O-acetylresveratrol.

Nitric oxide synthases (NOS), first reported by Bredt and Snyder (10) comprise the neuronal NOS (n-NOS), endothelial NOS (e-NOS) and inducible NOS (i-NOS) isoforms. The n-NOS and e-NOS are continuously expressed, whereas i-NOS expression is induced in organs (11). Once induced, i-NOS may lead to the upregulation of nitric oxide (NO) at a relatively constant rate for a long period of time. Excessive production of NO plays a crucial role in the process of inflammatory disease. Furthermore, several transcription factors were involved in $\mathrm{i}-\mathrm{NOS}$ gene expression and NF- $\mathrm{KB}$ is considered an essential factor $(12,13)$.

Resveratrol (3,5,4'-trihydroxy-trans-stilbene, Res) is a polyphenolic compound, which is a phytoalexin synthesized by a wide variety of plant species. Res has broad biological and pharmacological functions, such as cardioprotection (14), liver protection (15), radiation protection (16), anti-cancer (17), anti-aging (18), anti-oxidation (19) and neuro-protection (20). Therefore, interest of the scientific community in resveratrol has substantially increased. However, owing to its poor pharmacokinetic, bio-availability properties and short halflife of 8-14 min, resveratrol cannot be used as an injury protective drug (21). 3,5,4'-tri-O-acetylresveratrol (AC-Res) (Fig. 1), obtained by the complete acetylation of resveratrol, is a prodrug of resveratrol. Previous findings confirmed that AC-Res triggers the accumulation and concentration of resveratrol in lung (22).

Based on the abovementioned findings, we hypothesized and proved that the abnormal expression of NF- $\mathrm{kB}$ and i-NOS, followed by enhanced inflammatory response, played a critical role in SW-ALI. Additionally, the pretreatment of AC-Res may improve the outcome of SW-ALI through interference of the $\mathrm{NF}-\mathrm{\kappa B}$ and i-NOS pathways.

\section{Materials and methods}

Reagents. AC-Res with an HPLC purity of $>99 \%$, was obtained from Department of Medicinal Chemistry, School of Pharmacy, Fourth Military Medical University (Xi'an, Shaanxi, China). Seawater (osmolality $1,300 \mathrm{mmol} / 1$, $\mathrm{pH}$ 8.2, SW 1.05, $\mathrm{NaCl}_{2} 6.518 \mathrm{~g} / 1, \mathrm{MgSO}_{4} 3.305 \mathrm{~g} / 1, \mathrm{MgCl}_{2}$ $2.447 \mathrm{~g} / 1, \mathrm{CaCl}_{2} 1.141 \mathrm{~g} / \mathrm{l}, \mathrm{KCl} 0.725 \mathrm{~g} / 1, \mathrm{NaHCO}_{3} 0.202 \mathrm{~g} / 1$, $\mathrm{NaBr} 0.083 \mathrm{~g} / \mathrm{l}$ ) was prepared as per the composition of the East China Sea provided by the Chinese Ocean Bureau. Additionally, seawater was filtered prior to inspiration by the animals. Enzyme-linked immune adsorbent assay (ELISA) kits of TNF- $\alpha$ and interleukin-1 $\beta$ (IL-1 $\beta$ ) were purchased from R\&D Systems Inc. (Minneapolis, MN, USA). The NO assay kit was obtained from Jiancheng Bioengineering Institute (Nanjing, Jiangsu, China). Anti-pNF- $\kappa \mathrm{B}$ p65, anti-i-NOS and anti- $\beta$-actin monoclonal antibodies were purchased from Santa Cruz Biotechnology, Inc. (Santa Cruz, CA, USA). Other chemicals were of high purity and were used without purification.

Animals. Male adult Sprague-Dawley (SD) rats, weighing 180-220 g each, were obtained from the Animal Center of the Fourth Military Medical University. The rats were acclimatized to their environment for 1 week and housed in air-filtered, temperature-controlled units with free access to standard rodent chow and water. The experimental protocols were approved by the Animal Care and Use Committee of the Fourth Military Medical University and all experiments complied with the Declaration of the National Institutes of Health Guide for Care and Use of Laboratory Animals (publication no. 85-23, revised 1985).

Experimental group. Thirty-two SD rats were randomly divided into four groups. Rats in the control $(\mathrm{Ct})$ group were treated without any intervention. In the seawater inhalation (SW) group, seawater inhalation-induced ALI models were established in rats. Briefly, the rats were anesthetized with pentobarbital sodium [100 $\mathrm{mg} / \mathrm{kg}$ of body weight, administered intraperitoneally (i.p.)] and maintained in the supine position during the experiment with the head elevated at $30^{\circ}$. A syringe $(1 \mathrm{ml})$ was inserted into the trachea and seawater $(4 \mathrm{ml} / \mathrm{kg})$ was instilled at a steady speed within 4 min into the lungs.

Rats from the seawater inhalation plus 3,5,4'-tri-O-acetylresveratrol pretreatment (SW + AC-Res) group were pretreated with AC-Res (50 mg/ $\mathrm{kg}$ body weight) for 7 days prior to modeling. SW-ALI models were established $90 \mathrm{~min}$ after the previous administration of AC-Res and the modeling process was the same as that of the SW group.

In the fourth group, the rats were treated with $50 \mathrm{mg} / \mathrm{kg}$ AC-Res for 7 days. These rats were euthanized $90 \mathrm{~min}$ after the final administration of AC-Res.

The rats that suffered from seawater stimulation were anesthetized and exsanguinated through aortic transection $4 \mathrm{~h}$ after modeling. The lungs were removed rapidly from the thoraxes and processed as described below.

Histologic examination. The rats were sacrificed $4 \mathrm{~h}$ after seawater exposure ( $\mathrm{n}=8$ in each group). The same right lower lung lobes from all the animals were preserved in $4 \%$ formalin for $24 \mathrm{~h}$ and then embedded in paraffin. Lung tissues were cut into $5 \mu \mathrm{m}$ sections with a microtome and stained with hematoxylin and eosin after deparaffinisation and dehydration. Microscopic evaluation was performed to characterize the lung injury.

Wet to dry weight ratio of lung samples. In order to quantify the magnitude of pulmonary edema, we evaluated the wet to dry weight ratios of the lung samples from each group. Samples were obtained $4 \mathrm{~h}$ after seawater instillation and weighed immediately after removal prior to being subjected to desiccation in an oven at $70^{\circ} \mathrm{C}$ until a stable dry weight was 

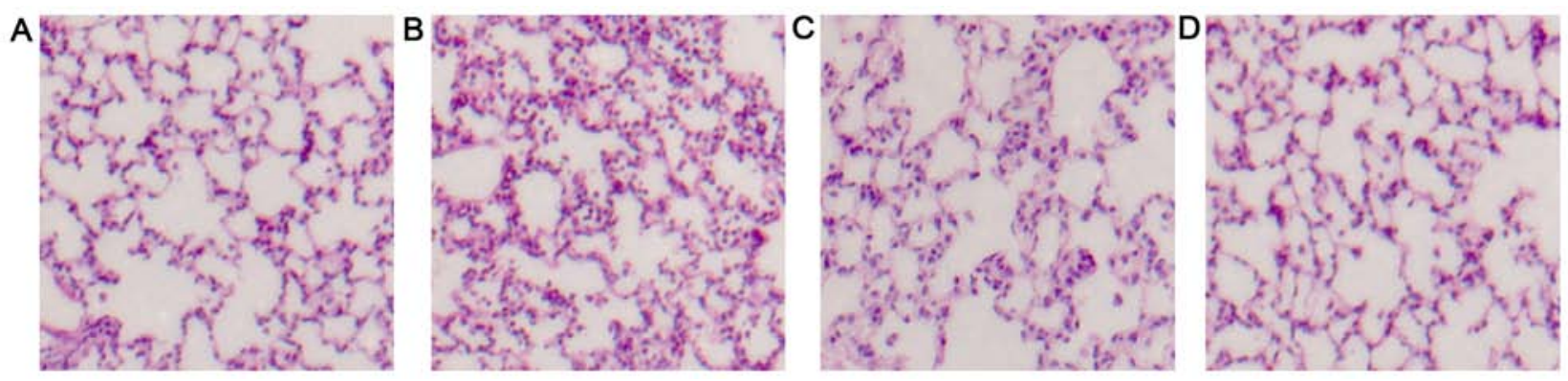

Figure 2. Effects of 3,5,4'-tri-O-acetylresveratrol on seawater exposure-induced lung histopathologic changes (hematoxylin and eosin stain, x200). (A) Ct. (B) SW. (C) Seawater inhalation plus 3,5,4'-tri-O-acetylresveratrol pretreatment group. (D) 3,5,4'-tri-O-acetylresveratrol group. Ct, control group; $\mathrm{SW}$, seawater inhalation group.

achieved after $72 \mathrm{~h}$. Wet to dry weight ratios were calculated to evaluate the level of pulmonary edema.

Bronchoalveolar lavage fluid (BALF) analysis. Lungs were removed intact and lavaged with $7 \mathrm{ml}$ ice-cold phosphate-buffered saline (PBS) 5 times $4 \mathrm{~h}$ after seawater inhalation. The recover ratio of PBS was $>90 \%$. BALF from each group was centrifuged at $500 \mathrm{x} \mathrm{g}$ for $10 \mathrm{~min}$ at $4^{\circ} \mathrm{C}$.

The protein content in the supernatant was determined by measuring the absorbance at $630 \mathrm{~nm}$ following the addition of bromocresol green. The values were calculated according to a standard curve and data were presented as $\mu \mathrm{g}$ protein $/ \mathrm{ml}(\mu \mathrm{g} / \mathrm{ml})$.

The cell pellet was resuspended in $1 \mathrm{ml}$ of red blood cell-lysis buffer to eliminate red cells. White cells were then re-pelleted by centrifugation at $520 \mathrm{x}$ g for $20 \mathrm{~min}$ at $4^{\circ} \mathrm{C}$. The cell pellet was again resuspended in PBS and cells were counted using a hemocytometer (XFA6100; Perlong Medical Equipment Co., Ltd., Nanjing, China).

Evaluation of vascular permeability. Vascular permeability was evaluated by extravasation of the Evans blue dye into lung tissues. Briefly, Evans blue $(20 \mathrm{mg} / \mathrm{kg})$ was administered intravenously $(1 \mathrm{ml} / \mathrm{kg})$ via a tail vein prior to modeling. Aliquots of lung tissues from each animal were dried in an oven for $24 \mathrm{~h}$ at $37^{\circ} \mathrm{C}$. Evans blue was then extracted in $1 \mathrm{ml}$ formamide for $24 \mathrm{~h}$ at room temperature. Evans blue contents were quantified by measuring absorbance at $620 \mathrm{~nm}$ and the concentration of Evans blue was calculated according to a standard curve $(1-100 \mathrm{mg} / \mathrm{ml})$. The results were presented as the amount of Evans blue $\mu \mathrm{g} / \mathrm{g}$ tissue.

NO content in lung. NO content, assessed by determining $\mathrm{NO} 2$ concentration in the plams of the lung tissues, reflected the degree of lung damage and expression of i-NOS. Briefly, the lung tissue samples were homogenized in cool normal saline (lung tissue to normal saline, 1:10). The homogenate was assessed according to the manufacturer's instructions. NO content was measured by absorbance at $550 \mathrm{~nm}$ and expressed as $\mathrm{mmol} / \mathrm{mg}$ protein.

Measurement of cytokines. TNF- $\alpha$ and IL-1 $\beta$ content were evaluated in the lung tissues collected at $4 \mathrm{~h}$ after seawater instillation. Briefly, portions of lung tissues were homogenized in cool phosphate-buffered saline (lung tissue to normal saline, 1:5). The assay was carried out using a commercially available ELISA kit, according to the manufacturer's instructions.

Cell culture and treatment. The NR8383 alveolar macrophage cell line, obtained from the American Type Culture Collection (ATCC, Rockville, MD, USA), was maintained in Ham's F12 medium supplemented with $10 \%$ fetal calf serum, $100 \mathrm{U} / \mathrm{ml}$ of penicillin and $100 \mu \mathrm{g} / \mathrm{ml}$ of streptomycin at $37^{\circ} \mathrm{C}$ in a humidified atmosphere containing $5 \% \mathrm{CO}_{2}$ and $95 \%$ air. The cells were stimulated with seawater $(25 \%)$ for $4 \mathrm{~h}$ with or without resveratrol $(40 \mu \mathrm{g} / \mathrm{ml})$ pretreatment. The total protein was extracted from the cells to evaluate the expression of $\mathrm{p}-65 \mathrm{NF}-\mathrm{\kappa B}$ and i-NOS on a protein level. Additionally, cytokines and NO content in medium were tested by ELISA and nitrate reductive enzymatic method, and the results were expressed as $\mathrm{pg} / \mathrm{ml}$ and $\mu \mathrm{mol} / 1$, respectively.

Western blot analysis. Lungs were perfused to remove the blood cells from pulmonary circulation. Tissue samples from each group were collected and the total proteins were extracted. Proteins from the lung samples and cells were quantified using a BCA protein assay kit. Subsequently, $100 \mu \mathrm{g}$ protein from each group was boiled in loading buffer. The proteins from each group were loaded and separated on a $12 \%$ SDS-PAGE gel, transferred to nitrocellulose membranes, blocked with 5\% non-fat dry milk in Tris-buffered saline with Tween-20 and probed overnight at $4^{\circ} \mathrm{C}$ with antibodies against p65NF- $\mathrm{B}(1: 1,000)$, i-NOS $(1: 500)$ and $\beta$-actin $(1: 5,000)$. The secondary antibody (anti-rabbit IgG peroxidase conjugated, 1:10,000) was incubated and the relative content of the target proteins was detected by the enhanced chemiluminescent detection system according to the manufacturer's protocol.

Statistical analysis. Data were presented as means \pm SD. Statistical analysis was performed with analysis of variance. Statistically significant differences between groups were identified using one-way ANOVA followed by the Dunnett's test. A statistical difference was accepted as significant if $\mathrm{P}<0.05$.

\section{Results}

Effects of AC-Res on histopathological changes. No histological alteration was observed in the lung tissues in the $\mathrm{Ct}$ group (Fig. 2A). Alveolar damage, pulmonary edema 


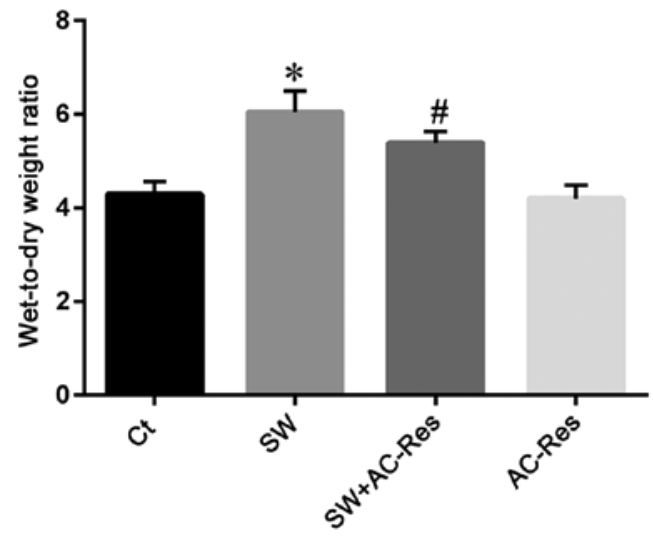

Figure 3. Effects of AC-Res on wet to dry weight ratios of lungs exposed to seawater. ${ }^{*} \mathrm{P}<0.01$ vs. $\mathrm{Ct}$; ${ }^{\#} \mathrm{P}<0.01$ vs. ${ }^{\mathrm{P}}$. $\mathrm{Ct}$, control group; $\mathrm{SW}$, seawater inhalation group; SW + AC-Res, seawater inhalation plus 3,5,4'-tri-Oacetylresveratrol pretreatment group; AC-Res, 3,5,4'-tri-O-acetylresveratrol group. Data are presented as means $\pm \mathrm{SD}, \mathrm{n}=8$.
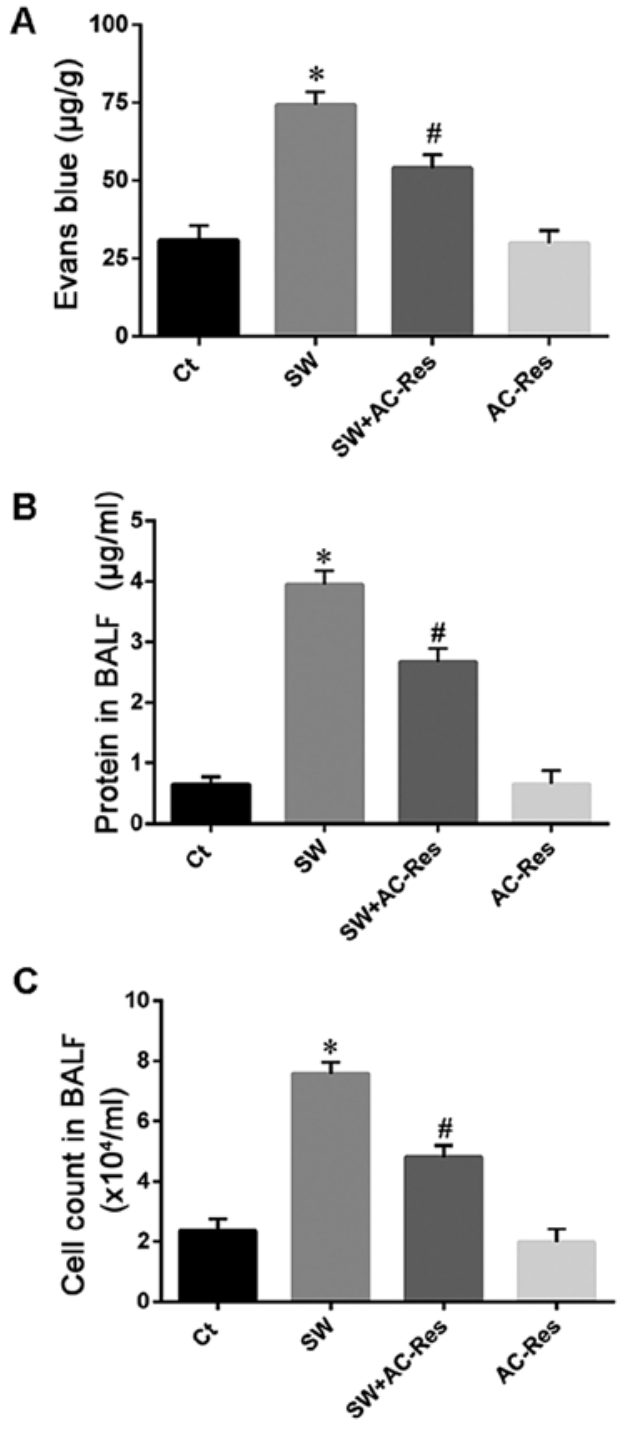

Figure 4.Effects of AC-Res on (A) Evans blue, (B) protein and (C) cell infiltration from blood vessels to lung tissues. ${ }^{*} \mathrm{P}<0.01$ vs. $\mathrm{Ct}$; ${ }^{\#} \mathrm{P}<0.01$ vs. ${ }^{*} \mathrm{P}$. $\mathrm{Ct}$, control group; SW, seawater inhalation group; SW + AC-Res, seawater inhalation plus 3,5,4'-tri-O-acetylresveratrol pretreatment group; AC-Res, 3,5,4'-tri-Oacetylresveratrol group. Data are presented as means $\pm \mathrm{SD}, \mathrm{n}=8$. and infiltration of inflammatory cells in the lung tissues and alveoli were evident $4 \mathrm{~h}$ after seawater instillation (Fig. 2B). AC-Res significantly reduced pulmonary edema and alveolar damage and inhibited inflammatory cells and blood cell infiltration (Fig. 2C).

Effects of AC-Res on lung edema. To observe lung edema resulting from seawater inhalation and the protective effects of AC-Res, we measured the lung wet to dry weight ratios of the tissues from each group (Fig. 3). The ratios were significantly increased in the seawater exposure group compared with the control group $(\mathrm{n}=8, \mathrm{P}<0.05)$. Compared with $\mathrm{SW}$, the wet to dry ratio of the AC-Res group was significantly decreased $(\mathrm{P}<0.05)$.

Effects of AC-Res on vascular permeability. Vascular permeability was evaluated to determine the reason for lung edema and to assess the effects of AC-Res (Fig. 4). The results showed that seawater stimulation increased the protein content in BALF (Fig. 4A), enhanced Evans blue dye and cell infiltration from blood vessels to lung tissues (Fig. 4B and C). By contrast, AC-Res pretreatment reduced the protein content in BALF and inhibited Evans blue and cell infiltration $(n=8, P<0.05)$.

AC-Res attenuates seawater resulted in inflammation. To determine the reason for the increase in vascular permeability, inflammation in lung samples was examined. The contents of TNF- $\alpha$ and IL-1 $\beta$ in lung tissues were tested using ELISA (Fig. 5). The results showed that seawater inspiration increased inflammatory TNF- $\alpha$ and IL- $1 \beta$ in lung tissues $(n=8$, $\mathrm{P}<0.05)$. By contrast, AC-Res treatment reduced the seawater stimulation, resulting in cell infiltration and TNF- $\alpha$ and IL-1 $\beta$ in lungs stimulated by seawater.

The results from the NR8383 cells showed that seawater stimulation increased TNF- $\alpha$ and IL-1 $\beta$ (Fig. 6) secretion. AC-Res treatment inhibited the release of those cytokines $(\mathrm{P}<0.05)$.

AC-Res reduced NO content. Since NO is associated with inflammation and plays an important role in the body, we investigated the effects of seawater on $\mathrm{NO}$ content and whether AC-Res attenuated that effect (Fig. 7A). The results showed that seawater inhalation increased the NO production $(\mathrm{n}=8$, $\mathrm{P}<0.05$ ), while AC-Res pre-treatment decreased NO content compared with that of SW $(\mathrm{n}=8, \mathrm{P}<0.05)$.

On the other hand, NO content in medium significantly increased when NR8383 cells were challenged with seawater (Fig. 7B). In addition, AC-Res pre-treatment reduced NO production $(\mathrm{P}<0.05)$.

Effects of AC-Res on $p-65 N F-\kappa B$ and $i-N O S$ expression in lung. Western blot analysis was performed to examine the status of p-65 NF- $\kappa$ B and i-NOS expression as well as the effects of AC-Res. The results (Figs. 8 and 9) showed that seawater instillation significantly upregulated the expression of $\mathrm{p}-65 \mathrm{NF}-\mathrm{kB}$ and $\mathrm{i}-\mathrm{NOS}(\mathrm{P}<0.05)$, while the pretreatment of AC-Res reversed the trend and decreased p- $65 \mathrm{NF}-\mathrm{\kappa B}$ and i-NOS at the protein level $(\mathrm{P}<0.05)$.

Similarly, the p-65 NF- $\mathrm{KB}$ and i-NOS expression levels were enhanced in the NR8383 cells following stimulation with seawater (Figs. 10 and 11). AC-Res inhibited the expres- 

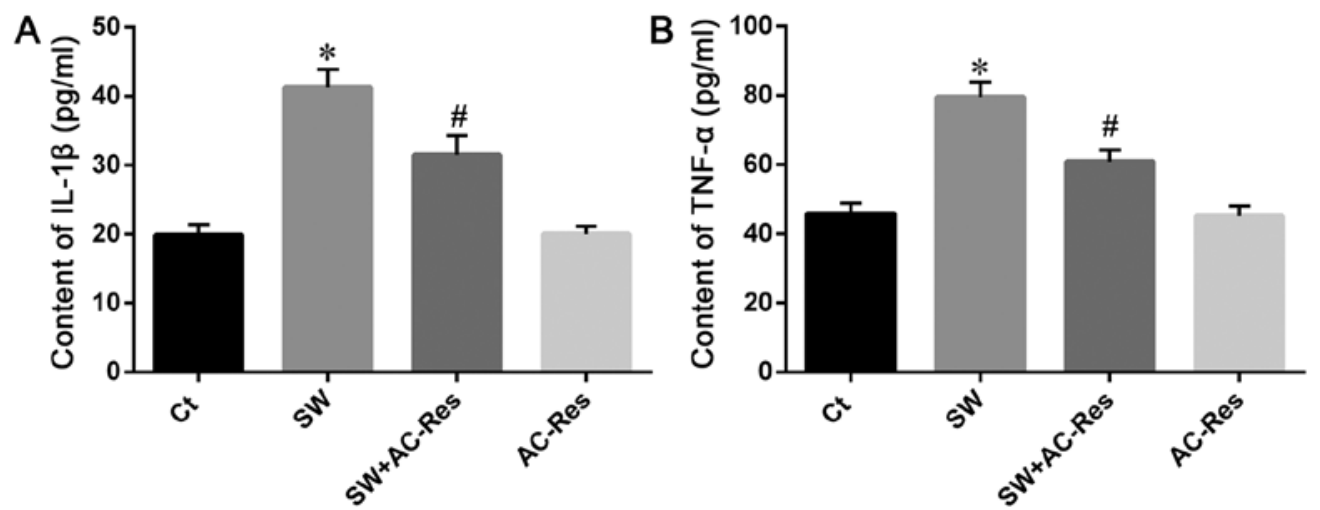

Figure 5. Effects of AC-Res on (A) IL-1 $\beta$ and (B) TNF- $\alpha$ contents in lung tissues. Data are presented as means $\pm \mathrm{SD}, \mathrm{n}=8$. ${ }^{*} \mathrm{P}<0.01 \mathrm{vs}$. Ct; ${ }^{~} \mathrm{P}<0.01$ vs. ${ }^{~} \mathrm{P}$. Ct, control group; SW, seawater inhalation group; SW + AC-Res, seawater inhalation plus AC-Res pretreatment group; AC-Res, 3,5,4'-tri-O-acetylresveratrol group.
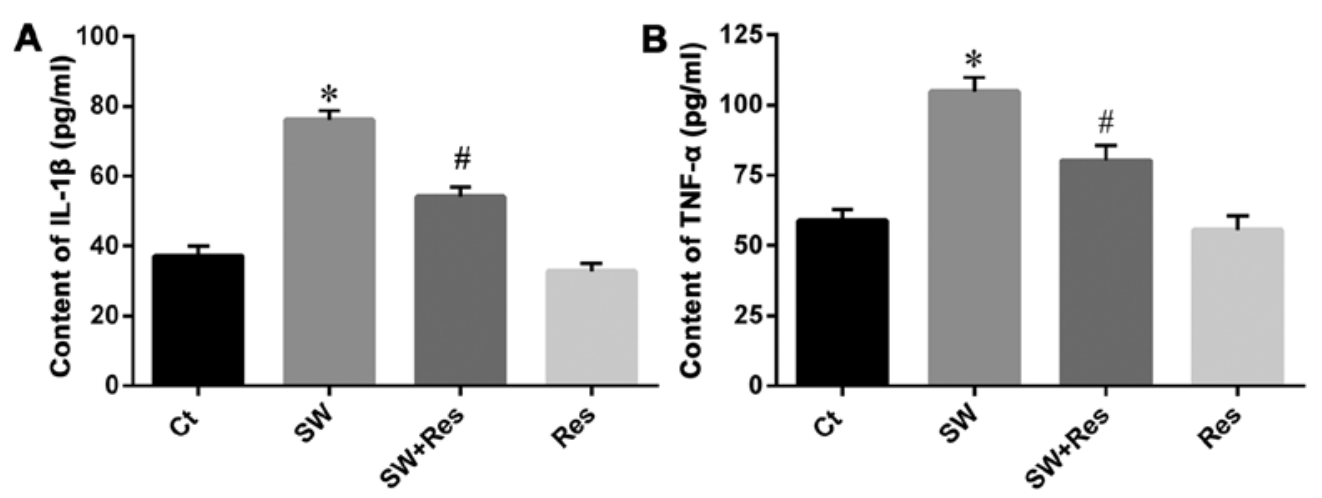

Figure 6. Effects of resveratrol on (A) IL-1 $\beta$ and (B) TNF- $\alpha$ secretion in NR8383 cells. Data are presented as means $\pm \mathrm{SD}, \mathrm{n}=8$. ${ }^{*} \mathrm{P}<0.01 \mathrm{vs}$. Ct; ${ }^{*} \mathrm{P}<0.01 \mathrm{vs}$. ${ }^{*} \mathrm{P}$. $\mathrm{Ct}$, control group; SW, seawater inhalation group; Res $+\mathrm{SW}$, seawater inhalation plus resveratrol pretreatment group; Res, resveratrol group.
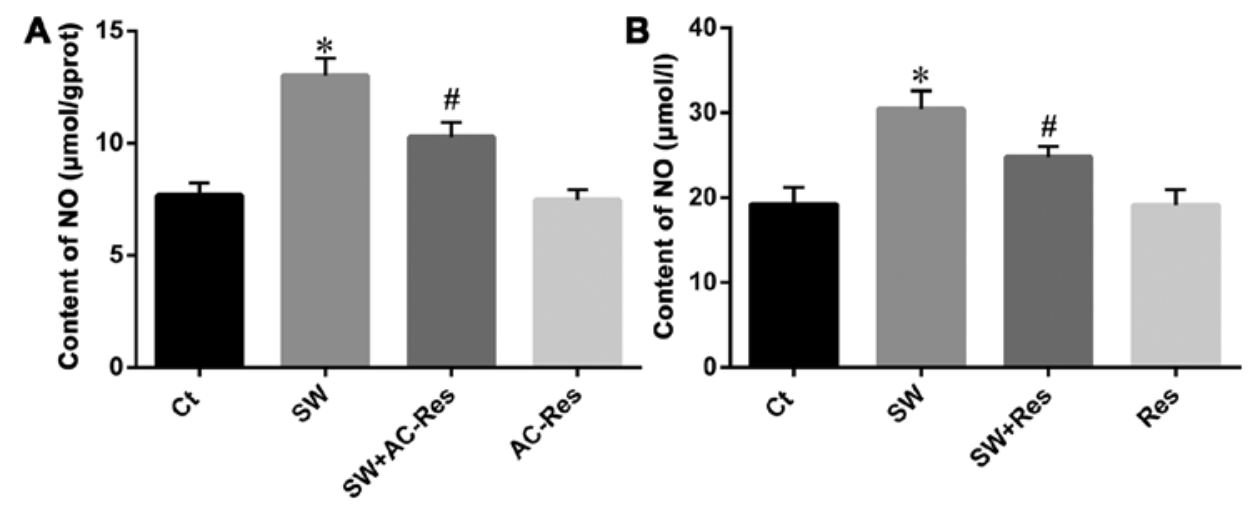

Figure 7. Effects of AC-Res and resveratrol on NO content in (A) lung tissues and (B) NR8383 cells. Data are presented as means $\pm \mathrm{SD}, \mathrm{n}=8 .{ }^{*} \mathrm{P}<0.01 \mathrm{vs}$. Ct; ${ }^{\#} \mathrm{P}<0.01$ vs. "P. Ct, control group; SW, seawater inhalation group; SW + AC-Res, seawater inhalation plus AC-Res pretreatment group; AC-Res, 3,5,4'-triO-acetylresveratrol group, SW + Res, resveratrol pretreatment plus seawater inhalation group; Res, resveratrol group.

sion of $\mathrm{p}-65 \mathrm{NF}-\mathrm{kB}$ and $\mathrm{i}-\mathrm{NOS}$ in cells challenged with seawater $(\mathrm{P}<0.05)$.

\section{Discussion}

Drowning is one of the most frequent causes of accidental mortality, while the mortality of near-drowning is $9-12 \%$ according to a large series of studies on near-drowning (23). Victims surviving the near-drowning process, may suffer
ALI characterized by alveolar collapse, atelectasis and intrapulmonary shunting. Seawater instillation-related lung damage is much more adverse than that of fresh water (24). Therefore, in the present study, we selected rats as experimental models, which survived seawater intratracheal instillation, to examine the potential mechanism of SW-ALI and the effects of AC-Res on it.

Resveratrol (3,5,4'- trihydroxy-trans-stilbene) is a polyphenolic compound, which is a phytoalexin synthesized 


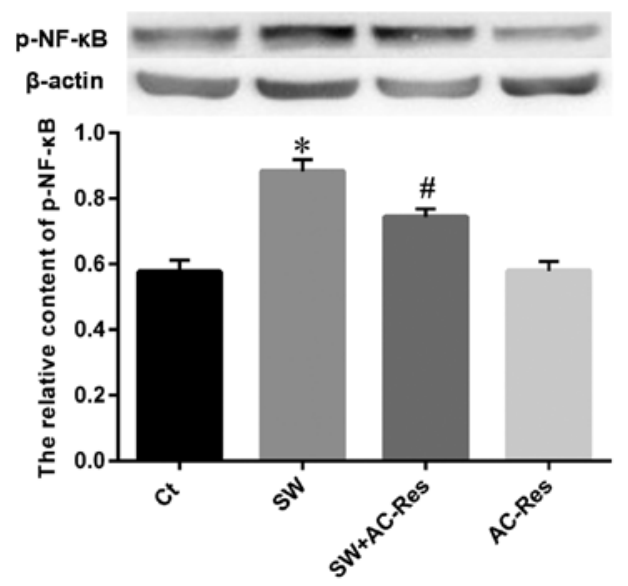

Figure 8. Effects of AC-Res on p-65 NF- $\mathrm{kB}$ expression in lung tissues. After protein quantitation, western blot analysis was performed to investigate the $\mathrm{p}-\mathrm{NF}-\mathrm{kB}$ content at $4 \mathrm{~h}$ after seawater administration. The ratios of $\mathrm{p}-\mathrm{NF}-\mathrm{\kappa B}$ protein vs. $\beta$-actin in three independent experiments were obtained by density scanning using an image analysis system. ${ }^{*} \mathrm{P}<0.01$ vs. $\mathrm{Ct}$; ${ }^{\text {"}} \mathrm{P}<0.01$ vs. ${ }^{\text {P }} \mathrm{P}$. $\mathrm{Ct}$, control group; $\mathrm{SW}$, seawater inhalation group; SW + AC-Res, seawater inhalation plus AC-Res pretreatment group; AC-Res, 3,5,4'-tri-O-acetylresveratrol group.

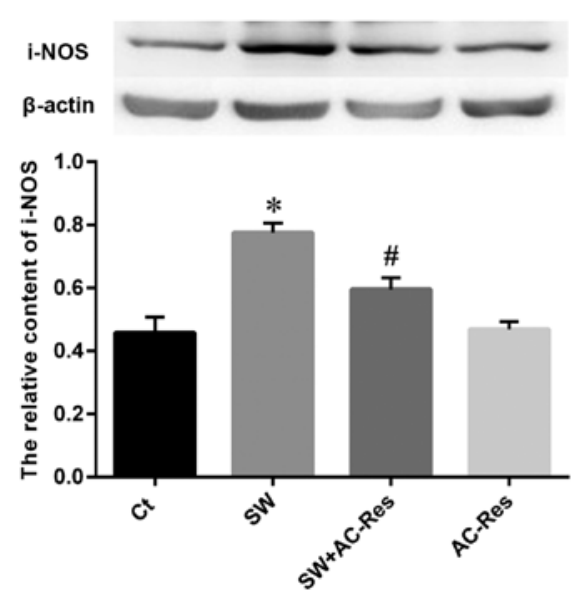

Figure 9. Effects of AC-Res on i-NOS expression in lung tissues. The ratios of i-NOS protein vs. $\beta$-actin in three independent experiments were obtained by density scanning using an image analysis system. ${ }^{*} \mathrm{P}<0.01 \mathrm{vs.} \mathrm{Ct}$; ${ }^{\text {" }} \mathrm{P}<0.01 \mathrm{vs}$ "P. Ct, control group; SW, seawater inhalation group; SW + AC-Res, seawater inhalation plus AC-Res pretreatment group; AC-Res, 3,5,4'-tri-O-acetylresveratrol group.

by a wide variety of plant species. Resveratrol has a number of pharmacological activities, including anti-oxidation (19) and anti-inflammation (25). However, resveratrol has limitations. For example, it is not stable with a short half-life and low bioavailability (21). Resveratrol's analog, AC-Res, with three hydroxyls replaced by acetyls, may overcome that disadvantage to some extent. Evidence has demonstrated that it exerted anti- $\gamma$-irradiation effects by inhibiting the expression of reactive oxygen species (ROS) (26). Additionally, in a previous study it was demonstrated that acetylated resveratrol attenuated SW-ALI by interfering with intracellular communication (27) and the HIF-1 $\alpha$ pathway (28). The aim of the present study was to examine the values of the NF- $\mathrm{KB}$ and i-NOS pathways in SW-ALI and the effects of AC-Res in seawater-stimulated lungs.

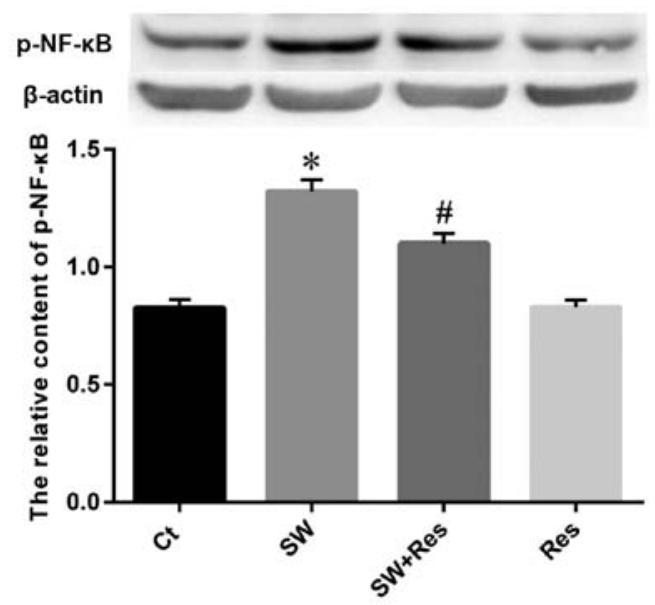

Figure 10. Effects of resveratrol on $\mathrm{p}-65 \mathrm{NF}-\kappa \mathrm{B}$ expression in NR8383 cells. The ratios of $\mathrm{p}-\mathrm{NF}-\kappa \mathrm{B}$ protein vs. $\beta$-actin in three independent experiments were obtained by density scanning using an image analysis system. ${ }^{*} \mathrm{P}<0.01$ vs. Ct; ${ }^{\#} \mathrm{P}<0.01$ vs. "P. $\mathrm{Ct}$, control group; SW, seawater inhalation group; SW + Res, resveratrol pretreatment plus seawater inhalation group; Res, resveratrol group.

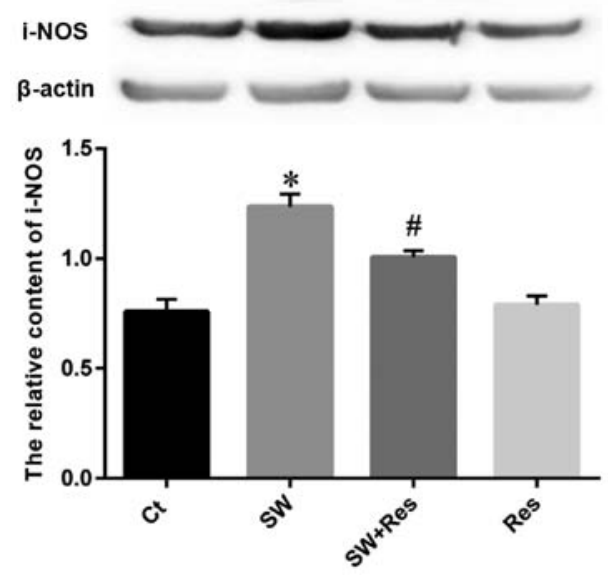

Figure 11. Effects of resveratrol on i-NOS expression in NR8383 cells. The ratios of i-NOS protein vs. $\beta$-actin in three independent experiments were obtained by density scanning using an image analysis system. ${ }^{*} \mathrm{P}<0.01$ vs. Ct; ${ }^{\#} \mathrm{P}<0.01$ vs. ${ }^{*} \mathrm{P}$. $\mathrm{Ct}$, control group; $\mathrm{SW}$, seawater inhalation group; SW + Res, resveratrol pretreatment plus seawater inhalation group; Res, resveratrol group.

Following seawater inspiration into lungs, the high osmolality caused osmotic fluid transport, driving fluid from the vascular to alveolar space, which led to lung edema. Our previous results proved that seawater inhalation led to an increased wet to dry weight ratio of lung and an abnormal expression of water-transporting proteins (29). Notably, the fluid accumulation in alveolar space also impaired oxygen diffusion followed by severe hypoxia, manifested by decreased $\mathrm{PaO}_{2}$, increased $\mathrm{PaCO}_{2}(30,31)$ and upregulation of HIF-1 $\alpha$ expression (32). Pulmonary inflammation may develop based on those changes and previous evidence from our laboratory and other investigators have shown that seawater increased cytokines and genes regulating inflammation.

Evidence has suggested that NF- $\mathrm{KB}$ activation is a crucial part of the pathological response that leads to the development 
of organ dysfunction/injury. It has also been consistently demonstrated, using an LPS model of septic shock, that septic shock may be improved by blocking the NF- $\kappa \mathrm{B}$ pathway, from $0-20 \%$ (LPS alone) to $80-100 \%$ (LPS plus NF- $\mathrm{B}$ inhibitors) (33). On the other hand, as NF- $\kappa \mathrm{B}$-dependent pro-inflammatory cytokines, TNF- $\alpha$ and IL-1 $\beta$ are involved in lung injury by promoting endothelial cell permeability, enhancing neutrophil recruitment and inducing further cytokine secretion. Positive feedback between NF- $\kappa \mathrm{B}$ and TNF- $\alpha$ and IL-1 $\beta$ may also enhance the inflammatory response. In the present study, we have demonstrated that seawater inspiration upregulated NF- $\kappa \mathrm{B}$ expression followed by increased TNF- $\alpha$ and IL-1 $\beta$ secretion, while pretreatment with AC-Res inhibited the expression of $\mathrm{NF}-\kappa \mathrm{B}$ and associated proinflammatory cytokines. By contrast, seawater-stimulated NR8383 cells also increased NF- $\kappa \mathrm{B}$ expression and the secretion of TNF- $\alpha$ and IL-1 $\beta$. Since AC-Res was altered prior to exhibiting its pharmacological effects, resveratrol was employed to determine the protective role of cells. The results showed that $\mathrm{NF}-\kappa \mathrm{B}$ expression was upregulated followed by enhancement of cytokine secretion, while resveratrol inhibited NF- $\kappa \mathrm{B}$ expression and reduced TNF- $\alpha$ and IL- $1 \beta$ secretion.

Evidence suggests that NF- $\kappa \mathrm{B}$ regulated $\mathrm{i}-\mathrm{NOS}$ activation was responsible for generating NO $(11,13)$. Furthermore, NO was closely associated with inflammation $(13,34)$. Previous findings have demonstrated smoke inhalation increased i-NOS expression (35) while the de-regulation of i-NOS was beneficial to Escherichia coli sepsis-induced lung inflammation and injury (36). We measured i-NOS expression, in the present study, to determine the downstream signals of $\mathrm{NF}-\kappa \mathrm{B}$ and results from the SW-ALI models and NR8383 cells showed that seawater inspiration significantly increased i-NOS expression and NO generation followed by enhanced inflammatory factor secretion. The pre-treatment of AC-Res was able to reduce i-NOS expression and NO generation through the $\mathrm{NF}-\kappa \mathrm{B}$ pathway. Similar results were obtained in seawater-stimulated NR8383 cells with or without resveratrol pretreatment.

The NF- $\kappa \mathrm{B}$ and i-NOS pathways were responsible for SW-ALI. Seawater inhalation increased NF- $\kappa$ B expression followed by the upregulation of i-NOS expression, NO formation and cytokine secretion. However, the pretreatment of AC-Res inhibited activation of the NF- $\kappa$ B and i-NOS pathways and attenuated lung edema and pulmonary inflammation in lungs challenged with seawater.

\section{Acknowledgements}

This study was supported by grants from the Military Key Projects in the 12th Five-year Plan of China (Project No. WS13J043).

\section{References}

1. Xinmin D, Yunyou D, Chaosheng P, Huasong F, Pingkun Z, Jiguang M, Zhiqian X and Qinzhi X: Dexamethasone treatment attenuates early seawater instillation-induced acute lung injury in rabbits. Pharmacol Res 53: 372-379, 2006.

2. Simcock AD: Treatment of near drowning - a review of 130 cases. Anaesthesia 41: 643-648, 1986

3. Erickson SE, Martin GS, Davis JL, Matthay MA and Eisner MD; NIH NHLBI ARDS Network: Recent trends in acute lung injury mortality: 1996-2005. Crit Care Med 37: 1574-1579, 2009.
4. Grünig G, Corry DB, Leach MW, Seymour BW, Kurup VP and Rennick DM: Interleukin-10 is a natural suppressor of cytokine production and inflammation in a murine model of allergic bronchopulmonary aspergillosis. J Exp Med 185: 1089-1099, 1997.

5. Zhang M, Wang L, Dong M, Li Z and Jin F: Endothelial Semaphorin 7A promotes inflammation in seawater aspirationinduced acute lung injury. Int J Mol Sci 15: 19650-19661, 2014.

6. Gregorakos L, Markou N,Psalida V,Kanakaki M, Alexopoulou A, Sotiriou E, Damianos A and Myrianthefs P: Near-drowning: clinical course of lung injury in adults. Lung 187: 93-97, 2009.

7. Nakatani K, Takeshita S, Tsujimoto H, Kawamura Y and Sekine I: Inhibitory effect of serine protease inhibitors on neutrophil-mediated endothelial cell injury. J Leukoc Biol 69: 241-247, 2001.

8. Hayden MS and Ghosh S: NF-кB in immunobiology. Cell Res 21: 223-244, 2011.

9. Li DY, Xue MY, Geng ZR and Chen PY: The suppressive effects of Bursopentine (BP5) on oxidative stress and NF- $\kappa$ B activation in lipopolysaccharide-activated murine peritoneal macrophages. Cell Physiol Biochem 29: 9-20, 2012.

10. Bredt DS and Snyder SH: Isolation of nitric oxide synthetase, a calmodulin-requiring enzyme. Proc Natl Acad Sci USA 87: 682-685, 1990.

11. Vaporidi K, Francis RC, Bloch KD and Zapol WM: Nitric oxide synthase 3 contributes to ventilator-induced lung injury. Am J Physiol Lung Cell Mol Physiol 299: L150-L159, 2010.

12. Kinaci MK, Erkasap N, Kucuk A, Koken T and Tosun M: Effects of quercetin on apoptosis, NF- $\kappa \mathrm{B}$ and NOS gene expression in renal ischemia/reperfusion injury. Exp Ther Med 3: 249-254, 2012.

13. Tabassum R, Vaibhav K, Shrivastava P, Khan A, Ahmed ME, Ashafaq M, Khan MB, Islam F, Safhi MM and Islam F: Perillyl alcohol improves functional and histological outcomes against ischemia-reperfusion injury by attenuation of oxidative stress and repression of COX-2, NOS-2 and NF- $\kappa \mathrm{B}$ in middle cerebral artery occlusion rats. Eur J Pharmacol 747: 190-199, 2015.

14. Rivera L, Morón R, Zarzuelo A and Galisteo M: Long-term resveratrol administration reduces metabolic disturbances and lowers blood pressure in obese Zucker rats. Biochem Pharmacol 77: 1053-1063, 2009

15. Wang T, Zhou ZX, Sun LX, Li X, Xu ZM, Chen M, Zhao GL, Jiang ZZ and Zhang LY: Resveratrol effectively attenuates $\alpha$-naphthyl-isothiocyanate-induced acute cholestasis and liver injury through choleretic and anti-inflammatory mechanisms. Acta Pharmacol Sin 35: 1527-1536, 2014.

16. Kim KO, Park H, Chun M and Kim HS: Immunomodulatory effects of high-protein diet with resveratrol supplementation on radiation-induced acute-phase inflammation in rats. J Med Food 17: 963-971, 2014.

17. Seino M, Okada M, Shibuya K, Seino S, Suzuki S, Takeda H, Ohta $\mathrm{T}$, Kurachi $\mathrm{H}$ and Kitanaka C: Differential contribution of ROS to resveratrol-induced cell death and loss of self-renewal capacity of ovarian cancer stem cells. Anticancer Res 35: 85-96, 2015.

18. Harikumar KB and Aggarwal BB: Resveratrol: A multitargeted agent for age-associated chronic diseases. Cell Cycle 7: 1020-1035, 2008

19. de la Lastra CA and Villegas I: Resveratrol as an antioxidant and pro-oxidant agent: Mechanisms and clinical implications. Biochem Soc Trans 35: 1156-1160, 2007.

20. Parker AJ, Arango M, Abderrahmane S, Lambert E, Tourette C, Catoire $\mathrm{H}$ and Néri C: Resveratrol rescues mutant polyglutamine cytotoxicity in nematode and mammalian neurons. Med Sci (Paris) 21: 556-557, 2005 (In French).

21. Walle T, Hsieh F, DeLegge MH, Oatis JE Jr and Walle UK: High absorption but very low bioavailability of oral resveratrol in humans. Drug Metab Dispos 32: 1377-1382, 2004.

22. Liang L, Liu X, Wang Q, Cheng S, Zhang S and Zhang M: Pharmacokinetics, tissue distribution and excretion study of resveratrol and its prodrug 3,5,4'-tri-O-acetylresveratrol in rats. Phytomedicine 20: 558-563, 2013.

23. Ellis AA and Trent RB: Hospitalizations for near drowning in California: Incidence and costs. Am J Public Health 85: 1115-1118, 1995.

24. Kakizaki E, Kozawa S, Sakai M and Yukawa N: Bioluminescent bacteria have potential as a marker of drowning in seawater: Two immersed cadavers retrieved near estuaries. Leg Med Tokyo 11: 91-96, 2009.

25. Poulsen MM, Fjeldborg K, Ornstrup MJ, Kjær TN, Nøhr MK and Pedersen SB: Resveratrol and inflammation: Challenges in translating pre-clinical findings to improved patient outcomes. Biochim Biophys Acta 1852: 1124-1136, 2015. 
26. Koide K, Osman S, Garner AL, Song F, Dixon T, Greenberger JS and Epperly MW: The use of 3,5,4'-Tri-O-acetylresveratrol as a potential pro-drug for resveratrol protects mice from $\gamma$-irradiationinduced death. ACS Med Chem Lett 2: 270-274, 2011.

27. Ma L, Li Y, Zhao Y, Wang Q, Nan Y, Mu D, Li W, Sun R, Jin F and Liu X: 3,5,4'-tri-O-acetylresveratrol ameliorates seawater exposure-induced lung injury by upregulating connexin 43 expression in lung. Mediators Inflamm 2013: 182132, 2013.

28. Ma L, Zhao Y, Li B, Wang Q, Liu X, Chen X, Nan Y, Liang L, Chang R, Liang L, et al: 3,5,4'-Tri-O-acetylresveratrol attenuates seawater aspiration-induced lung injury by inhibiting activation of nuclear factor- $\kappa \mathrm{B}$ and hypoxia-inducible factor- $1 \alpha$. Respir Physiol Neurobiol 185: 608-614, 2013.

29. Li J, Xu M, Fan Q, Xie X, Zhang Y, Mu D, Zhao P, Zhang B, Cao F, Wang Y, et al: Tanshinone IIA ameliorates seawater exposure-induced lung injury by inhibiting aquaporins (AQP) 1 and AQP5 expression in lung. Respir Physiol Neurobiol 176: 39-49, 2011.

30. Zhang Y,Zhang B, Xu DQ, Li WP, Xu M,Li JH, Xie XY, Fan QX, Liu W, Mu DG, et al: Tanshinone IIA attenuates seawater aspiration-induced lung injury by inhibiting macrophage migration inhibitory factor. Biol Pharm Bull 34: 1052-1057, 2011.

31. Li JH, Xu M, Xie XY, Fan QX, Mu DG, Zhang Y, Cao FL, Wang YX, Zhao PT, Zhang B, et al: Tanshinone IIA suppresses lung injury and apoptosis, and modulates protein kinase B and extracellular signal-regulated protein kinase pathways in rats challenged with seawater exposure. Clin Exp Pharmacol Physiol 38: 269-277, 2011.
32. Zhang M, Dong M, Liu W, Wang L, Luo Y, Li Z and Jin F: 1 $\alpha, 25-$ dihydroxyvitamin D3 ameliorates seawater aspiration-induced acute lung injury via NF- $\mathrm{BB}$ and RhoA/Rho kinase pathways. PLoS One 9: e104507, 2014.

33. Zheng C, Yin Q and Wu H: Structural studies of NF- $\kappa B$ signaling. Cell Res 21: 183-195, 2011.

34. Vaibhav K, Shrivastava P, Javed H, Khan A, Ahmed ME, Tabassum R, Khan MM, Khuwaja G, Islam F, Siddiqui MS, et al: Piperine suppresses cerebral ischemia-reperfusion-induced inflammation through the repression of COX-2, NOS-2, and $\mathrm{NF}-\kappa \mathrm{B}$ in middle cerebral artery occlusion rat model. Mol Cell Biochem 367: 73-84, 2012.

35. Cox RA, Jacob S, Oliveras G, Murakami K, Enkhbaatar P, Traber L, Schmalstieg FC, Herndon DN, Traber DL and Hawkins HK: Pulmonary expression of nitric oxide synthase isoforms in sheep with smoke inhalation and burn injury. Exp Lung Res 35: 104-118, 2009.

36. Brovkovych V, Gao XP, Ong E, Brovkovych S, Brennan ML, Su X, Hazen SL, Malik AB and Skidgel RA: Augmented inducible nitric oxide synthase expression and increased NO production reduce sepsis-induced lung injury and mortality in myeloperoxidase-null mice. Am J Physiol Lung Cell Mol Physiol 295: L96-L103, 2008. 